Florida International University FIU Digital Commons

All Faculty

$5-2-2016$

\title{
Rapid in vivo measurement of B-amyloid reveals biphasic clearance kinetics in an Alzheimer's mouse model
}

Carla M. Yuede

Washington University School of Medicine

Hyo Lee

Washington University School of Medicine

Jessica L. Restivo

Washington University School of Medicine

Todd A. Davis

Washington University School of Medicine

Jane C. Hettinger

Washington University School of Medicine

See next page for additional authors

Follow this and additional works at: https://digitalcommons.fiu.edu/all_faculty

\section{Recommended Citation}

Yuede, Carla M.; Lee, Hyo; Restivo, Jessica L.; Davis, Todd A.; Hettinger, Jane C.; Wallace, Clare E.; Young, Katherine L.; Hayne, Margaret R.; Bu, Guojun; Li, Chen-zhong; and Cirrito, John R., "Rapid in vivo measurement of B-amyloid reveals biphasic clearance kinetics in an Alzheimer's mouse model" (2016). All Faculty. 120.

https://digitalcommons.fiu.edu/all_faculty/120

This work is brought to you for free and open access by FIU Digital Commons. It has been accepted for inclusion in All Faculty by an authorized administrator of FIU Digital Commons. For more information, please contact dcc@fiu.edu. 


\section{Authors}

Carla M. Yuede, Hyo Lee, Jessica L. Restivo, Todd A. Davis, Jane C. Hettinger, Clare E. Wallace, Katherine L. Young, Margaret R. Hayne, Guojun Bu, Chen-zhong Li, and John R. Cirrito 


\title{
Rapid in vivo measurement of $\beta$-amyloid reveals biphasic clearance kinetics in an Alzheimer's mouse model
}

\author{
Carla M. Yuede ${ }^{1}$ Hyo Lee, ${ }^{1}$ Jessica L. Restivo, ${ }^{1}$ Todd A. Davis, ${ }^{1}$ Jane C. Hettinger, ${ }^{1}$ Clare E. Wallace,${ }^{1}$ \\ Katherine L. Young, ${ }^{1}$ Margaret R. Hayne, ${ }^{1}$ Guojun Bu, ${ }^{2}$ Chen-zhong Li, ${ }^{3}$ and John R. Cirrito ${ }^{1}$ \\ 'Department of Neurology, Hope Center for Neurological Disorders, Knight Alzheimer's Disease Research Center, Washington University School of Medicine, \\ St. Louis, M0 63110 \\ ${ }^{2}$ Department of Neuroscience, Mayo Clinic, Jacksonville, FL 32224 \\ ${ }^{3}$ Nanobioengineering/Bioelectronics Laboratory, Department of Biomedical Engineering, Florida International University, Miami, FL 33199
}

Findings from genetic, animal model, and human studies support the observation that accumulation of the $\beta$-amyloid (A $\beta$ ) peptide in the brain plays a central role in the pathogenic cascade of Alzheimer's disease (AD). Human studies suggest that one key factor leading to accumulation is a defect in brain $A \beta$ clearance. We have developed a novel microimmunoelectrode (MIE) to study the kinetics of $A \beta$ clearance using an electrochemical approach. This is the first study using MIEs in vivo to measure rapid changes in $A \beta$ levels in the brains of living mice. Extracellular, interstitial fluid (ISF) A $\beta$ levels were measured in the hippocampus of APP/PS1 mice. Baseline levels of $A \beta_{40}$ in the ISF are relatively stable and begin to decline within minutes of blocking A $\beta$ production with a $\gamma$-secretase inhibitor. Pretreatment with a P-glycoprotein inhibitor, which blocks blood-brain barrier transport of $A \beta$, resulted in significant prolongation of $A \beta_{40}$ half-life, but only in the latter phase of $A \beta$ clearance from the ISF.

Accumulation of $\beta$-amyloid $(A \beta)$ in the brain is an initiating factor in the pathological cascade leading to the development and progression of Alzheimer's disease (AD; Musiek and Holtzman, 2015). High concentrations of $A \beta$ promote its aggregation into toxic species, such as oligomers and fibrils, within the brain extracellular space. The balance between $A \beta$ generation and elimination determines the concentration of $A \beta$ in the brain interstitial fluid (ISF). Four broad pathways have been identified that eliminate $A \beta$ from the brain transport across the blood-brain barrier $(\mathrm{BBB})$, proteolytic degradation, cellular uptake, and bulk flow clearance. Several of these pathways are impaired in individuals with $\mathrm{AD}$ (Preston et al., 2003; Nixon, 2007; van Assema et al., 2012). For instance, neprilysin and $\mathrm{P}$-glycoprotein, an $\mathrm{A} \beta$-degrading enzyme and an $\mathrm{A} \beta$ transporter at the $\mathrm{BBB}$, respectively, are significantly reduced in human AD brain (Wang et al., 2005; Deo et al., 2014). In mouse models, deletion of either of these proteins increases brain $A \beta$ levels, increases plaque load, and significantly prolongs the elimination rate of $A \beta$ (or halflife) from the brain (Cirrito et al., 2005; Farris et al., 2007). Clearance of $A \beta$ from the CSF is impaired in individuals with AD (Mawuenyega et al., 2010), strongly suggesting that a key factor leading to $A \beta$ accumulation is a defect in eliminating the peptide from the brain. $A \beta$ is secreted into the extracellular space, where it is soluble in the ISF under normal

Correspondence to John R. Cirrito: cirritoj@neuro.wustl.edu; or Carla M. Yuede: yuedec@neuro.wustl.edu

Abbreviations used: $A \beta, \beta$-amyloid; $A D$, Alzheimer's disease; BBB, blood-brain barrier; GSI, $\gamma$-secretase inhibitor; ISF, interstitial fluid; MIE, microimmunoelectrode; MMP, matrix metalloproteinase; Pgp, P-glycoprotein; SWV, square wave voltammetry. circumstances. The ISF pool of A $\beta$ gives rise to pathological species, so mechanisms that regulate $A \beta$ clearance from the ISF should impact $\mathrm{AD}$ pathogenesis. $\mathrm{A} \beta$ has a relatively short half-life compared with other proteins in the brain, indicating that some clearance mechanisms are fast-acting. Here, we use a novel microimmunoelectrode (MIE) to measure rapid changes in ISF A $\beta$ metabolism in vivo.

Studying the temporal kinetics of $A \beta$ within the brain ISF requires specialized techniques that specifically sample $A \beta$ only from the ISF with the exclusion of peptide in other brain compartments (e.g., intracellular or membrane-bound) and can measure $A \beta$ serially over time in a living mouse. In the past, we pioneered an in vivo microdialysis technique to measure ISF A $\beta$ levels every 60 min over $3-5 \mathrm{~d}$ in mice (Cirrito et al., 2003, 2011). Although hourly sampling is still very useful, some studies require even faster temporal resolution. We recently developed an electrochemical technique using MIEs to detect $\mathrm{A} \beta$ (Prabhulkar et al., 2012) and have adapted it to measure ISF $A \beta$ every $60 \mathrm{~s}$ over several hours in the brains of living mice.

\section{RESULTS AND DISCUSSION}

In vitro characterization of the MIE

Amperometry is an electrochemical technique used to measure oxidation of a wide range of molecules, most notably small molecules such as serotonin and dopamine in the brain (Wightman, 1988). Several national security biohazard de-

- 2016 Yuede et al. This article is distributed under the terms of an Attribution-Noncommercial-Share Alike-No Mirror Sites license for the first six months after the publication date (see $h t t p: / / w w w . r u p r e s s . o r g$ Alike-No Mirror Sites license for the first six months after the publication date (see http://www.rupress.org
/terms). After six months it is available under a Creative Commons License (Attribution-NoncommercialShare Alike 3.0 Unported license, as described at http://creativecommons.org/licenses/by-nc-sa/3.0/). 


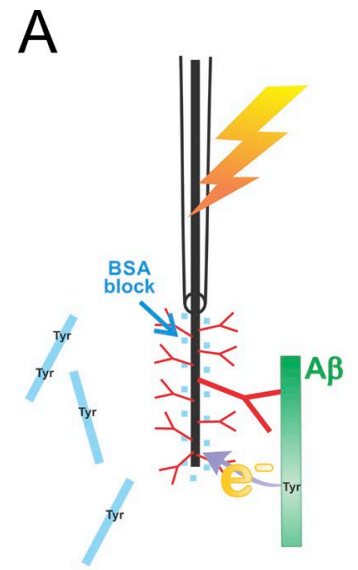

B

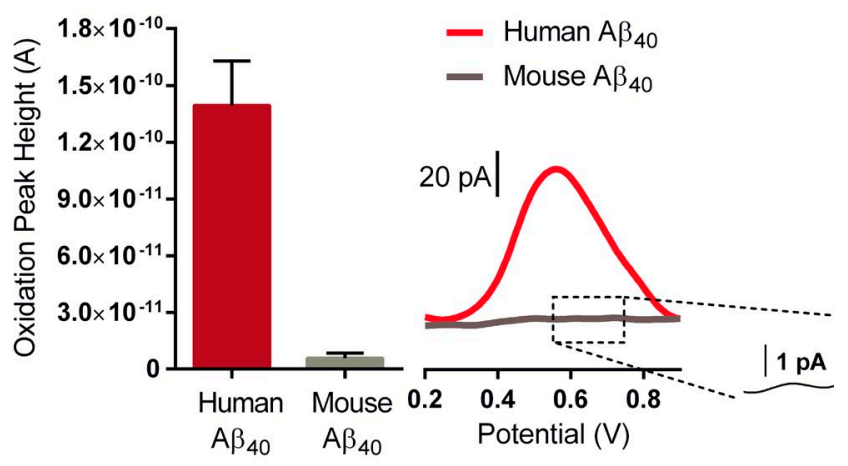

Figure 1. A $\boldsymbol{\beta}$-specific MIE. (A) Schematic of MIE. Anti-A $\beta$ antibodies are covalently attached to the electrode surface, and then unbound space is blocked with BSA. An electrode held at $0.65 \mathrm{~V}$ induces oxidation of Tyr amino acids. Oxidation releases an electron that the carbon fiber detects as current. The amount of current is proportional to the amount of Tyr present. Because many proteins in the extracellular space contain Tyr residues, the inclusion of an anti-A $\beta$ antibody is a necessary factor that determines specificity of the electrode. (B) Peak oxidation current of A $\beta$ MIE in matched concentrations of human and mouse $\mathrm{A} \beta(n=3$; mean $\pm \mathrm{SEM})$. tectors, such as for anthrax, use amperometry in combination with antibodies to make the chip-based sensors specific for a protein (Sadik et al., 2003). We have developed a similar amperometric, antibody-based approach to measure $A \beta$; however, these sensors can quantify a wide range of concentrations, take longitudinal measurements, and be implanted directly into the brain.

$\mathrm{A} \beta$ peptides in solution can be measured by exploiting the intrinsic electroactivity of A $\beta$ (Vestergaard et al., 2005). The single tyrosine (Tyr) residue at position 10 of human $A \beta$ bears a phenolic group that can be oxidized at an electrode surface. Oxidation releases electrons, which an electrode detects as current; the amount of current is directly proportional to the number of Tyr residues present, or the concentration. Using square wave voltammetry (SWV), the voltage applied to a carbon fiber microelectrode is step-wise increased from 0 to $1.0 \mathrm{~V}$. When the electrode scans through $\sim 0.65 \mathrm{~V}$, Tyr residues present in human $\mathrm{A} \beta$ oxidize, which is detected by the electrode as increased peak oxidation current. However, a $0.65-\mathrm{V}$ potential will oxidize a variety of molecules, including all nearby Tyr within other proteins. We covalently attached anti-A $\beta_{40}$ or anti- $\mathrm{A} \beta_{42}$ antibodies, $\mathrm{mHJ} 2$ and $\mathrm{mHJ} 7.4$, respectively, to the MIE surface to provide specificity for each target (Fig. 1 A). Albumin is then absorbed to the electrode surface to limit nonspecific signal. Tyr oxidation is irreversible, therefore, $A \beta$ peptides oxidized at the electrode surface can only be measured once. Additionally, once the tyrosine amino acids within albumin and antibody are initially oxidized, they will not contribute signal to the MIE over time.

The A $\beta$ MIE is a $5-\mu \mathrm{m}$-diam, 30-60- $\mu \mathrm{m}$-long cylindershape similar to the carbon fiber microelectrodes used in other in vivo studies (Roitman et al., 2008). Murine A $\beta$ lacks a Tyr at position 10 , so in theory, should not produce an oxidative signal using the MIE. As expected, robust oxidative signal is detected with the MIE in a solution of human $A \beta$, whereas only negligible signal is observed in a concentration-matched solution of murine $A \beta$ (Fig. 1 B). Post-hoc ELISAs were used to verify that the absolute concentration of murine and human $A \beta$ were equal in these solutions. Importantly, the $\mathrm{mHJ} 2$ anti-A $\beta_{40}$ anti- body on the MIE binds to both mouse and human $A \beta$ equally. Consequently, murine $A \beta$ and wild-type mice serve as important negative controls to identify how specific the MIEs are at detecting only human $\mathrm{A} \beta$ as opposed to other electroactive molecules and proteins.

The antibody attached to the electrode is particularly important, as it provides specificity for the target and strongly influences MIE longevity. For the MIE to function, there must be excess antibody capable of binding fresh target; however, if all of the antibodies are bound to $A \beta$, the electrode becomes nonfunctional. MIEs are an application in which antibodies with a moderate affinity are ideal, so that the target has both an on-rate as well as a reasonable off-rate, allowing antibody binding capacity to remain open so new $A \beta$ continues to bind. To prolong longevity of the MIE, we used an antibody specific for $\mathrm{A} \beta_{40}$ with moderate affinity $(\mathrm{mHJ} 2$ $\mathrm{KD}=14 \mathrm{nM}$ determined by surface plasmon resonance) to allow for dissociation.

For our initial in vitro studies, we attached a mouse monoclonal antibody specific for $A \beta_{40}(\mathrm{mHJ} 2)$ and evaluated the electrode response in solutions of $A \beta_{40}$ and $A \beta_{42}$ using SWV. Oxidation peak height increased as concentration of $A \beta_{40}$ increased (Fig. 2 A). At comparable concentrations in solution, the $A \beta_{40}$ MIE is 52 times more selective for $A \beta_{40}$ over $A \beta_{42}$ (Fig. 2 B). Similarly, attaching $\mathrm{mHJ}$ 7.4, an anti-A $\beta_{42}-$ specific antibody, we also saw an increase in peak height corresponding with increasing concentrations (Fig. 2 C). The A $\beta_{42}$ MIE is 15,000 times more selective for $A \beta_{42}$ than for $A \beta_{40}$ (Fig. $2 \mathrm{D}$ ). The higher selectivity of the $A \beta_{42}$ MIE is likely caused by the higher affinity of the antibody. This difference in selectivity is particularly important in vivo, where there are very low concentrations of $A \beta_{42}$ compared with $A \beta_{40}$. We have intentionally designed the MIEs to have widely different selectivity for $A \beta_{40}$ and $A \beta_{42}$ species to take into account practical considerations of electrode longevity and actual 40:42 ratios of the peptide in brain ISF. In the APP/PS1 mouse model used in these studies, the concentration of brain ISF $A \beta_{42}$ is 10 -fold lower than $A \beta_{40}$. Consequently, the $A \beta_{40}$ MIE actually has an effective 520-fold selectivity for $A \beta_{40}$ versus $A \beta_{42}$ in vivo. 
A

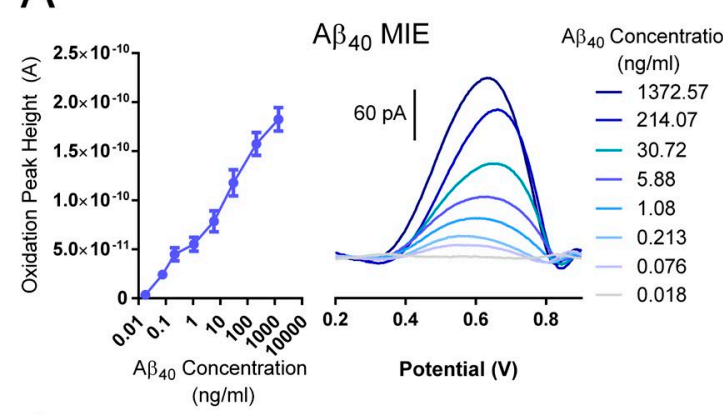

B

C

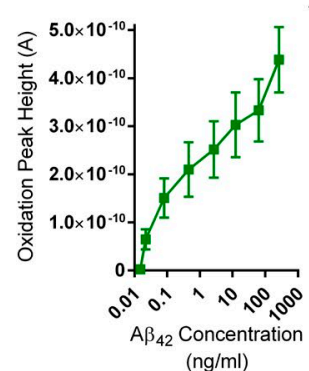

$A \beta_{42}$ MIE

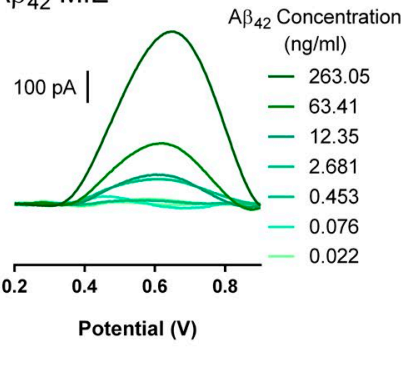

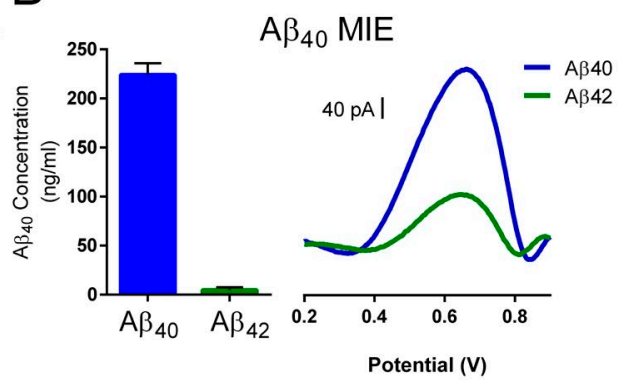

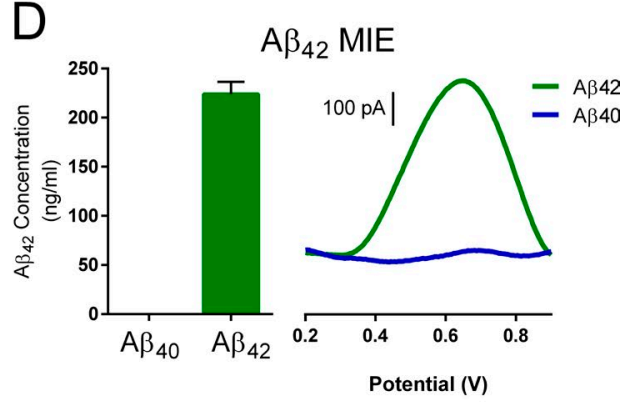

Figure 2. In vitro characterization of MIEs for $\mathbf{A} \boldsymbol{\beta}_{40}$ and $\mathbf{A} \boldsymbol{\beta}_{42}$. Oxidation peak height of MIEs coated with either $(A)$ an $A \beta_{40}$ specific antibody ( $\mathrm{mHJ} 2$; $n=6$ ) or (C) $A \beta_{42}$-specific antibody (mHJ7.4; $n=7$ ). (B) Representative concentration of $A \beta$ measured using $A \beta_{40}$ MIE in matched concentrations of $A \beta_{40}$ and $A \beta_{42}(n=3$; mean $\pm S E M)$. Representative concentration of $A \beta$ measured using $A \beta_{42}$ MIE in matched concentrations of $A \beta_{40}$ and $A \beta_{42}(n=3 ;$ mean $\pm S E M ; D)$.

\section{In vivo MIEs to measure brain ISF A $\beta$}

To measure rapid changes in brain ISF A $\beta$ in the mouse hippocampus, we stereotaxically implanted $\mathrm{A} \beta_{40}$ MIEs into the hippocampus of anesthetized APP/PS1 and wild-type mice (Fig. 3 A). A large oxidation peak is observed at $\sim 0.65 \mathrm{~V}$ in APP/PS1 mice, whereas only a negligible oxidative signal is seen in scans of wild-type mice (Fig. 3 B). Variability in individual MIE length and sensitivity leads to variable oxidation peak heights for each electrode; therefore, each MIE must be calibrated against known concentrations of $A \beta$. The mean concentration of human $A \beta_{40}$ in the ISF, as measured by the MIE, is $128.16 \mathrm{ng} / \mathrm{ml}$. Within a single animal, the minute-to-minute variability of $\mathrm{A} \beta$ is $9.89 \pm 1.88 \mathrm{ng} / \mathrm{ml}$ (mean \pm SEM). These fluctuations appear to be biologically driven by rapid changes in $A \beta$ production and clearance. In contrast, levels of murine $A \beta$ in wild-type mice are essentially undetectable (Fig. 3 C). From these data, we infer that the MIE is at least 8,000-fold more selective in vivo for human $\mathrm{A} \beta$ as opposed to any other Tyr present in the brain ISF.

To evaluate stability of the MIE in vivo over time, we normalized the concentration of ISF A $\beta$ at each time point to the mean baseline concentration from minute 10 to 25 for each mouse (Fig. 3 D). Concentrations are stable until minute 118, after which measurements have a small but significant decrease from baseline levels $(\mathrm{P}=0.02)$. These results indicate that the MIE loses sensitivity after $\sim 2 \mathrm{~h}$ in vivo; therefore, measurements beyond 120 min need to be corrected for this decease. The decrease in ISF A $\beta$ after $2 \mathrm{~h}$ appears to be pri- marily a result of electrode sensitivity and possibly a small reduction in ISF A $\beta$ levels caused by anesthesia. To verify using a complementary technique, we used in vivo microdialysis to measure ISF A $\beta$ every hour before and during isoflurane anesthesia. ISF A $\beta$ levels decrease by $14 \%$ during the first $3 \mathrm{~h}$ of isoflurane anesthesia; however, this was not a significant change in $\mathrm{A} \beta(n=4, \mathrm{P}=0.135)$. For the following MIE studies, we only sampled $A \beta$ for 100 min after implantation to avoid this confounding factor.

\section{MIE technology}

MIEs provide a powerful technology to assess the rapid dynamics of protein changes in brain within short periods. This provides a temporal resolution to measure proteins in vivo every $60 \mathrm{~s}$, which was previously not feasible. One of the advantages, and disadvantages, of the $\mathrm{A} \beta$ MIE technique is that it only detects human $A \beta$ species. Although wild-type mice serve as a negative control, this technique limits studies to those involving transgenic/knock-in mouse models that produce the human form of $A \beta$. The $5-\mu \mathrm{m}$-diam of the MIEs is smaller than most neuron cell bodies, so the electrodes create very little damage during insertion. Implantation of microelectrodes has been shown to activate microglia within $6 \mathrm{~h}$, but not within the short timeframe of our study (Kozai et al., 2012). We examined tissue sections for evidence of lesions or microbleeds resulting from acute MIE implantation; in many cases tissue disruption caused by surgery was evident on the brain surface; however, the exact site of the MIE tip was very 


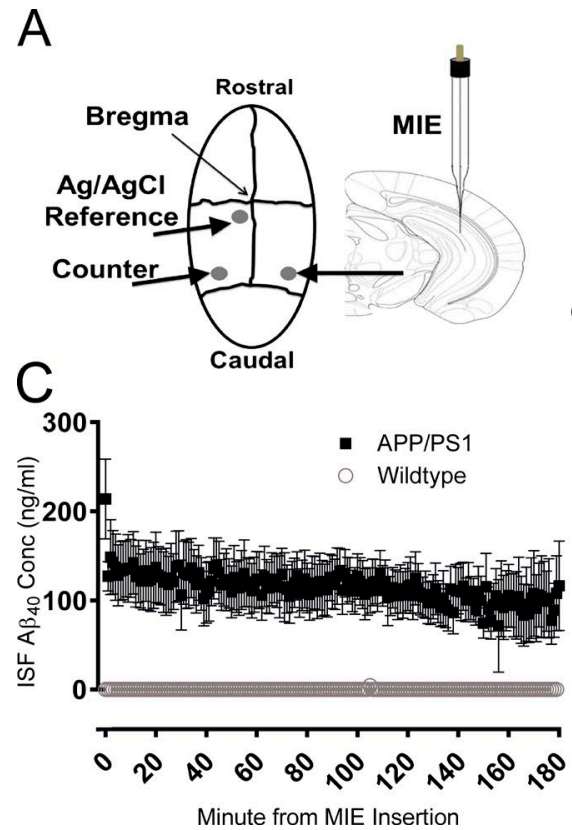

Minute from MIE Insertion
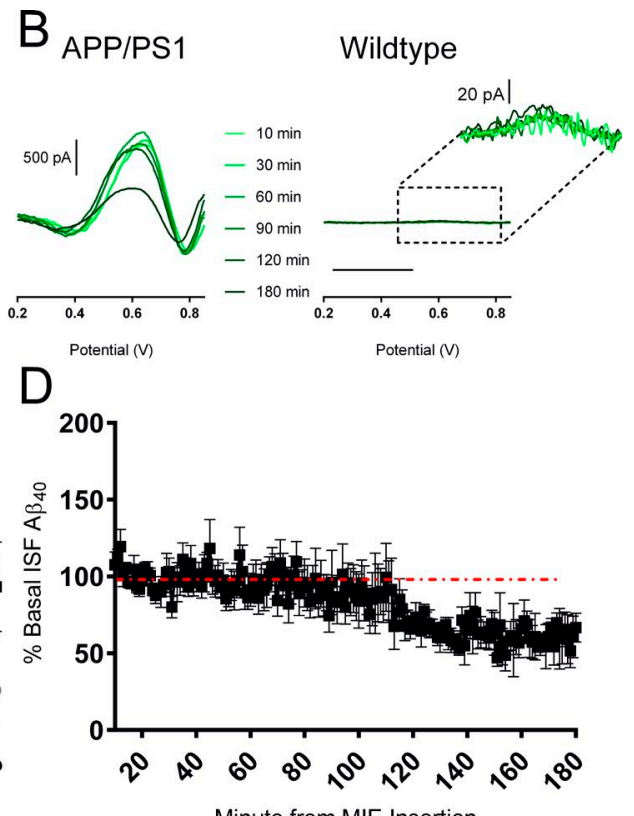

Figure 3. In vivo MIE measures ISF $A \boldsymbol{\beta}$ in APP/PS1 mouse model. (A) Stereotaxic placement of MIE, reference and counter electrodes on mouse skull, with representative SWV peaks from the hippocampus of an APP/PS1 mouse and WT littermate. (B) Traces measuring human and murine $A \beta$ with baseline subtraction are shown on the same scale to highlight the differences in peak height observed, while inset shows background level detected in the WT mouse. (C) ISF $A \beta_{40}$ concentrations over 180 min in APP/PS $(n=6)$ and WT $(n=3)$ mice. (D) Data in Panel $C$ normalized to percent of baseline ISF $A \beta_{40}$ levels of each APP/PS1 mouse show stable levels until 118 min after MIE insertion (ANOVA post hoc analysis, $\mathrm{P}=0.02$ ). small and normally undetectable by histology. Consequently, tissue damage is only a small concern using this technique.

MIEs only function for $2 \mathrm{~h}$ before starting to lose sensitivity. In contrast, our in vivo microdialysis technique samples A $\beta$ every hour, but lasts for 3-5 d (Cirrito et al., 2003). The MIE and microdialysis approaches complement each other by enabling the study of both brief and prolonged events that regulate ISF A $\beta$ metabolism. Measuring protein concentrations every $60 \mathrm{~s}$ enables us to study fast-acting mechanisms for $\mathrm{A} \beta$ production and clearance, which could not previously be studied. Specificity of the electrode depends on the antibody attached and the presence of an electroactive amino acid (such as tyrosine, tryptophan, or cysteine); therefore, it is possible that MIEs can be developed to detect other proteins as well.

\section{Rapid measurement of $A \boldsymbol{\beta}$ half-life in vivo}

P-glycoprotein (Pgp) removes brain ISF A $\beta$ by transporting it across the BBB (Cirrito et al., 2005; Hartz et al., 2010). Pgp is expressed on the luminal surface of brain endothelial cells and transports the peptide out of those cells and into blood. Pgp-null mice (mdr1a/1b double knockout mice) have significantly impaired $\mathrm{BBB}$ transport of $\mathrm{A} \beta_{40}$; however, $A \beta_{42}$ transport is minimally affected. Pgp-null mice crossed to Tg2576 APP transgenic mice also have significantly greater plaque load, and similarly, individuals with low Pgp expression have higher $A \beta$ deposits in brain (Vogelgesang et al., 2002).

Using MIEs to measure real-time and rapid changes in ISF $A \beta_{40}$, we evaluated clearance under normal conditions and after Pgp inhibition. Previous studies in rodents have shown XR9576 effectively blocks Pgp-mediated transport quickly, with maximum activity inhibited $30 \mathrm{~min}$ after injection, which then declines slowly due to low compound elimination (Bankstahl et al., 2008). We measured levels of
XR9576 in brain tissue at $1 \mathrm{~h}$ after injection and found mean levels to be $533.0 \pm 68.11 \mu \mathrm{M}$, where the $\mathrm{IC}_{50}$ for inhibition in vivo is $1.05 \mu \mathrm{M}$ (Wanek et al., 2015). Therefore, we pretreated one group of APP/PS1 mice with XR9576 for $1 \mathrm{~h}$ before measuring $A \beta_{40}$ clearance. Under anesthesia, we inserted an $A \beta_{40}$ MIE into the hippocampus to measure baseline ISF A $\beta$ levels for 15 min before administering Compound $\mathrm{E}$, a $\gamma$-secretase inhibitor (GSI), to block $A \beta$ generation. Inhibiting Pgp alone resulted in a 305\% increase in baseline levels of $A \beta_{40}$ compared with controls (Fig. $4 \mathrm{~A}$ ). The increase in ISF $A \beta$ detected with the MIE is much greater than previous studies using microdialysis (Cirrito et al., 2005). This is likely because of the difference of awake versus anesthetized mice and because the two techniques detect slightly different populations of ISF $A \beta$ in vivo.

Treating mice with a GSI rapidly blocks $A \beta$ generation, enabling us to assess the elimination of existing peptide present within the ISF. From these data, we can calculate an in vivo elimination half-life of endogenous $A \beta$. Although the absolute levels of $A \beta_{40}$ were significantly higher in the XR9576-treated mice, ISF A $\beta_{40}$ concentration still declined quickly after GSI treatment in both groups (Fig. 4 B). Compound E drug levels reach $395 \mathrm{nM}$ brain tissue within $5 \mathrm{~min}$ after intraperitoneal injection (Fig. 4 C). This concentration is $\sim 1,200$-fold higher than the $\mathrm{IC}_{50}$ of Compound $\mathrm{E}$ to block APP cleavage into $\mathrm{A} \beta$ ( $\mathrm{IC}_{50}$ in $\mathrm{CHO}$ cells is $300 \mathrm{pM}$; Seiffert et al., 2000). Compound E levels in the brain decrease substantially by $60 \mathrm{~min}$ after injection; however, they still remain 30-fold higher than the $\mathrm{IC}_{50}$ (Fig. $4 \mathrm{C}$ ). Percent changes in ISF $A \beta_{40}$ after GSI administration were transformed into $\log$ values to calculate rate of clearance over time (Fig. 4 D). We analyzed the overall rate of clearance in both groups from minutes $5-60$, which was significantly 

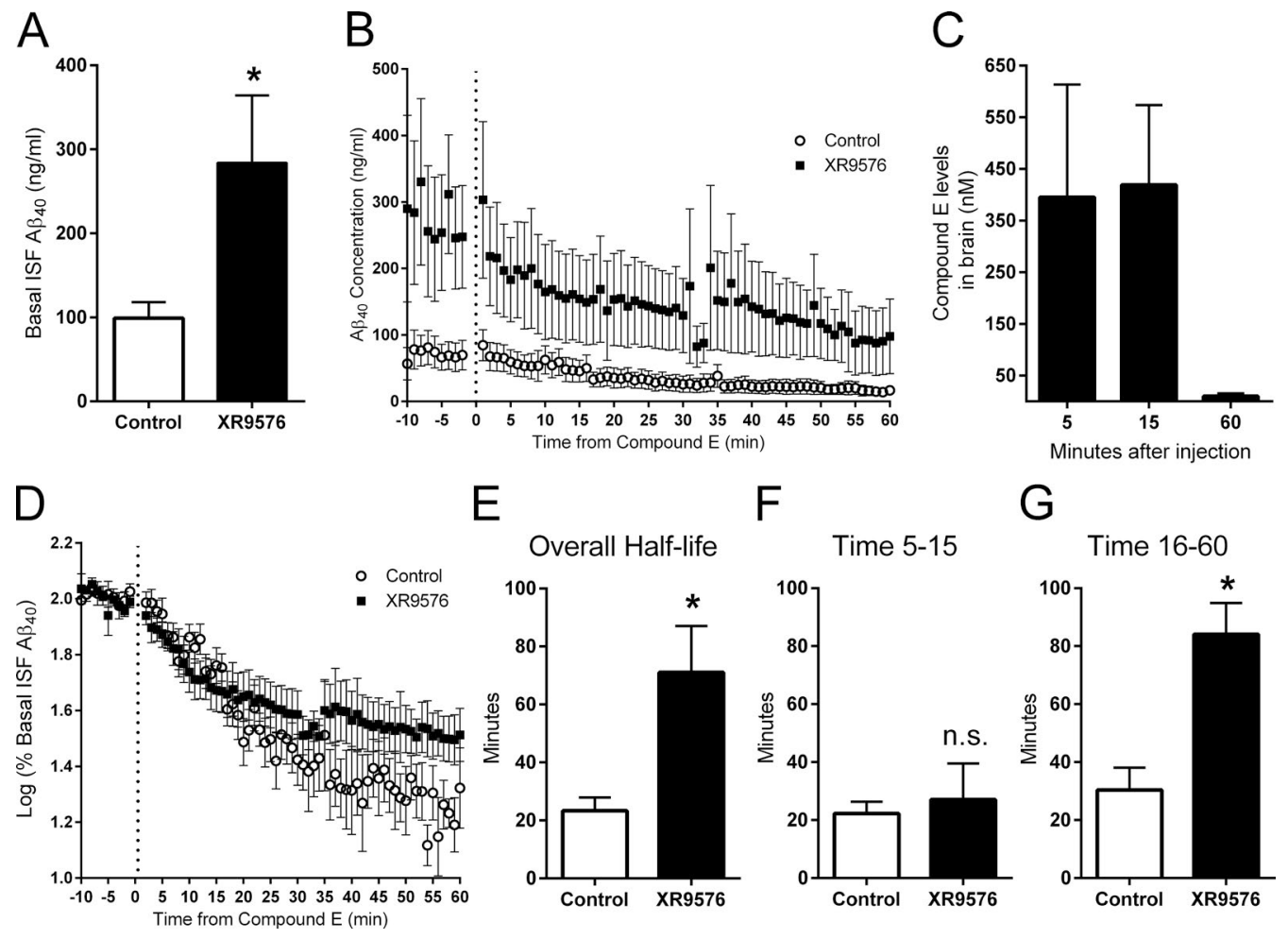

G

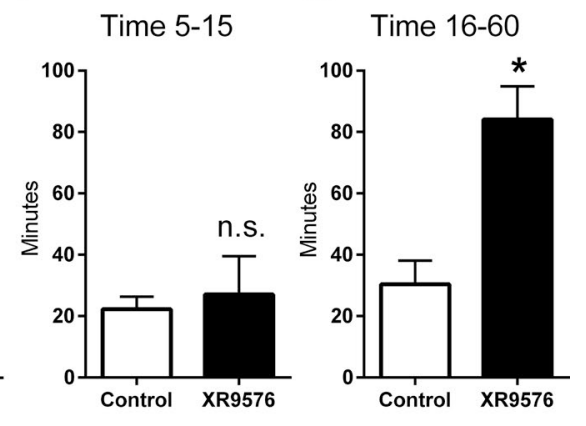

Figure 4. Rapid measurement of ISF $\mathbf{A} \boldsymbol{\beta}_{40}$ clearance after Pgp inhibition. (A) Absolute baseline concentrations of ISF A $\beta_{40}$ calculated using calibrated MIEs in the hippocampus of APP/PS1 mice are significantly increased (Student's $t$ test; $\left.{ }^{*}, P=0.008\right) 60$ min after XR9576 treatment $(n=8$; mean $=283.9$ $\pm 80.38 ; 80 \mathrm{mg} / \mathrm{kg})$ compared with control mice $(n=15$; mean $=99.12 \pm 19.28)$. (B) ISF A $\beta_{40}$ concentrations decrease in both groups after Compound $\mathrm{E}$ administration to block $A \beta$ production. (C) Compound $E$ levels in the brain reach $\sim 1,200$-fold $I C_{50}$ within 5 min of injection and remain $\sim 30$-fold higher than IC $\mathrm{C}_{50}$ at $60 \mathrm{~min}$. (D) Log plot of percent $A \beta$ change from baseline versus time for both XR9576-treated mice $(n=5)$ and control $(n=6)$ shows initial rates of clearance are very similar then begin to diverge $16 \mathrm{~min}$ after $\gamma$-secretase inhibition. (E) Overall half-life of $A \beta_{40}$ is significantly slowed (Student's $t$ test; ${ }^{*}, P=0.016$ ) after XR9576 treatment (control mean $=23.30 \pm 4.55 \mathrm{~min} ;$ XR9576 mean, $71.05 \pm 16.01 \mathrm{~min}$ ). Further analysis of the slopes between groups suggests two phases in $A \beta_{40}$ clearance over time. Statistical analysis reveals no difference in rates over the first 15 min ( $F ;$ Student's $t$ test, $P=0.698$; control mean $=22.26 \pm 4.09$ min; XR9576 mean, $27.1 \pm 12.41 \mathrm{~min}$ ); however, rates from 16-60 min are significantly slowed in XR9576-treated mice (G; Student's $t$ test; ${ }^{*}, \mathrm{P}=0.001$; control mean, $30.44 \pm 7.71 \mathrm{~min} ; \mathrm{XR9576}$ mean, $\left.84.08 \pm 10.85 \mathrm{~min}\right)$. Error bars represent $\pm \mathrm{SEM}$.

prolonged by $275 \%$ in the XR9576-treated mice compared with control mice ( $\mathrm{P}=0.012$; Fig. 4 E). The overall pattern of changes observed in ISF A $\beta$ after GSI administration and Pgp inhibition using the MIE are comparable to what we have previously reported (Cirrito et al., 2005).

Interestingly, however, the rates of clearance were not uniformly different throughout the entire course of the study; the semi-log plots of both groups actually show similar clearance rates up until $15 \mathrm{~min}$, where they then begin to diverge (Fig. 4 D). Using a modified curve stripping analysis, we isolated two different slopes in the clearance profile. We found no significant differences in the clearance rate during the initial 15 min after GSI treatment (Fig. 4 F); however, the second phase in the clearance rate (minutes 16-60) was significantly slower in XR9576-treated mice ( $\mathrm{P}=0.001$; Fig. 4 G). To determine if acute inhibition of Pgp influenced expression of low-density lipoprotein-1 (LRP1), or other genes related to APP processing or $A \beta$ clearance, we examined mRNA levels in brain tissue $2 \mathrm{~h}$ after XR 9756 treatment (see Materials and methods for specific genes). We did not find significant differences in mRNA expression levels in the brain, indicating the drug treatment is not affecting global expression of genes related to APP processing or A $\beta$ elimination ( $n=6 /$ group; $\mathrm{P}=0.08-0.94$; cut off for multiple comparisons, $\mathrm{P}=0.004$ ). Similarly, LRP1 protein levels did not change in hippocampus after XR9576 administration $(n=9 /$ group, $\mathrm{P}=0.35)$. However, we did not assess expression in blood vessels specifically. Pgp does not appear to play a substantial role in brain $A \beta$ clearance at high concentrations, but is a critical mechanism when $A \beta$ levels decrease below a certain threshold.

\section{Kinetics of $A \boldsymbol{\beta}$ clearance in vivo}

Clearance of $A \beta$ falls into four main categories: active BBB transport into the periphery, cellular uptake, proteolytic degradation, and passive bulk flow elimination. Both LRP1 and Pgp are expressed by endothelial cells (abluminally and luminally, respectively) and act cooperatively to transport $A \beta$ from the perivascular space out of the brain into blood (Shi- 
bata et al., 2000; Deane et al., 2004; Zlokovic et al., 2010) LRP1 and several family members have an additional role of cellular uptake of $A \beta$ within the brain (Castellano et al., 2012; Kanekiyo et al., 2013). Proteases such as neprilysin and matrix metalloproteinases (MMPs) degrade extracellular A $\beta$ (Farris et al., 2007). Lastly, bulk flow mechanisms, including the glymphatic system, clear A $\beta$ out of the ISF as part of the normal, passive fluid turnover (Xie et al., 2013).

By measuring ISF A $\beta$ very rapidly, we were able to detect multiple rates of $A \beta$ elimination from the brain. Our data using MIEs for rapid sampling determined that $A \beta$ clearance does not follow first-order kinetics, as previously reported by our group using microdialysis (Cirrito et al., 2003). Instead, the rate of elimination varies with concentration. The initial rate of clearance, when ISF A $\beta$ concentrations are high, has a very short half-life. However, as $A \beta$ concentrations decline, the half-life is significantly longer. It is possible that the various $A \beta$ clearance mechanisms contribute to different clearance rates. It will be necessary to explore these effects by blocking individual pathways and measuring rapid clearance to determine the role each mechanism plays in the immediate removal of $A \beta$ from the ISF. Our data demonstrate that Pgp is critical for the slower elimination rate of $A \beta$ at the $B B B$, which appears to account for an overall greater percentage of ISF $A \beta$ clearance than the faster pathway. These results are similar to those reported by (Qosa et al., 2014) in that BBB clearance accounts for a greater percentage of $A \beta_{40}$ clearance than proteolytic degradation, and Pgp inhibition slows this clearance pathway specifically.

Our data suggest that the speed and efficiency of $A \beta$ clearance pathways may be different. A therapeutic strategy aimed at rapid clearance at only high concentrations may be different than a strategy that is designed for a sustained, possibly larger, suppression of $A \beta$. And if multiple pathways are targeted, then enhancing clearance mechanisms with different properties and rates could be beneficial.

\section{MATERIALS AND METHODS}

Animals. All experimental procedures involving animals were approved by the Animal Studies Committee at Washington University. We bred APP/PS1 ${ }^{+/-}$hemizygous mice (Jankowsky et al., 2004) to wild-type C3H/B6 mice (The Jackson Laboratory), and then used the APP/PS1 $1^{+/-}$offspring, or wild-type littermates, for experiments at 3 mo of age, before $A \beta$ deposits are observed in this model. These mice contain a PS1 $\triangle E 9$ mutation and human APP Swedish mutation that were inserted into a single locus. Animals were screened for the PS1 and APP transgenes by polymerase chain reaction from tail DNA. Male and female littermate mice were distributed between experimental groups.

MIE preparation. MIEs were prepared following our previously described methods (Prabhulkar et al., 2012). Carbon fiber microelectrodes were used as the platform sensor because of their high signal-to-noise ratio, biological compati- bility, and small size. Carbon-based electrodes have also been proven to sensitively detect Tyr oxidation (Vestergaard et al., 2005). In brief, a single length of carbon fiber (5- $\mu$ m-diam; GoodFellow Corp.) was aspirated into a glass capillary tube (0.4-mm inner diameter, 4 inch length;A-M Systems), shaped using a pipette puller (Narishige PE-22), and attached to an insulated silver wire using conductive silver adhesive paste (Ted Pella, Inc.). The junction between the wire and the glass capillary tube was sealed using heat shrink tubing (NTE Electronics). The carbon fiber was cut using microsurgical scissors (World Precision Instruments, Inc.) to a length of 30-60 $\mu \mathrm{m}$. To enhance binding of the capture antibody, the microelectrodes were pretreated using a triangular waveform from 0 to $3 \mathrm{~V}$ for $70 \mathrm{~s}$ in PBS, or in $150 \mathrm{mM} \mathrm{NaCl}$ solution $(\mathrm{pH}, 10)$ at $1.2 \mathrm{~V}$ for $4 \mathrm{~min}$. The carboxylic groups on the carbon fiber surface were activated by application of $0.4 \mathrm{M}$ of EDC and 0.1 M of NHSS solutions (Thermo Fisher Scientific) to form a semistable reactive amine NHS ester. The activated microelectrodes are placed in a solution of antibody (e.g., mHJ2 for $A \beta_{40}$ or $\mathrm{mHJ7.4}$ for $\mathrm{A} \beta_{42}$ ) and incubated at room temp for $10 \mathrm{~min}$, and then $4^{\circ} \mathrm{C}$ overnight. After antibody attachment, MIEs were incubated with $0.05 \%$ ethanolamine to deactivate reactive amine sites and then $0.1 \%$ BSA to block nonspecific protein-binding sites.

In vitro MIE studies. In vitro calibration of the MIEs before experiments were conducted using a $\mathrm{CH}$ Instruments 660D Electrochemical Workstation with PicoAmp booster (CH Instruments Inc.). A conventional three-electrode cell consisting of an $\mathrm{Ag} / \mathrm{AgCl}$ reference electrode $(1 \mathrm{M} \mathrm{KCl})$, and a platinum wire as a counter electrode was used in all experimental procedures. Synthetic human $A \beta_{40}, A \beta_{42}$, and mouse $A \beta_{40}$ (American Peptide Co.) were prepared in fivefold serial dilutions ranging from $1 \mu \mathrm{g}$ to $64 \mathrm{pg}$ in $0.1 \% \mathrm{BSA}$ in PBS. SWV was used to monitor the response of the electrode in different concentrations of $A \beta$. Actual concentration in each $A \beta$ sample was determined by sandwich ELISA after each experiment. A $\beta$ concentrations using the MIE were calculated based on standard curve values from the calibration ELISA. SWV parameters used were: Init $\mathrm{E}(\mathrm{V})=0$; Final $\mathrm{E}(\mathrm{V})=1$; Inc.r $\mathrm{E}$ $(V)=0.004 ;$ Amplitude $(V)=0.04$; and Frequency $(\mathrm{Hz})=15$.

In vivo MIE studies. To maintain consistency with our in vitro characterization of the $A \beta_{40}$ MIE, we used a three electrode design in vivo as well. In addition to the MIE, a stainless steel bone screw used as a counter electrode, and an $\mathrm{Ag} / \mathrm{AgCl}$ reference electrode (InVivo Metrics) were implanted into the brain of preplaque (3-4 mo old) APP/PS1 ${ }^{+/-}$transgenic mice and wild-type littermates. All electrodes were stereotaxically implanted in to the brains of APP/PS1 ${ }^{+/-}$mice under isoflurane anesthesia. Mice were placed on a heating pad to maintain body temperature. For these experiments, $A \beta_{40}$ MIEs were inserted into the hippocampus at coordinates: bregma $-3.1 \mathrm{~mm}, 2.6 \mathrm{~mm}$ lateral to midline, and $1.7 \mathrm{~mm}$ below dura mater. Repetitive SWV scans were run every $60 \mathrm{~s}$ for 
up to $180 \mathrm{~min}$. The stereotax was enclosed in a faraday cage to reduce electrical noise. Electrodes were attached to a $\mathrm{CH}$ Instruments 830D Electrochemical Analyzer with PicoAmp booster. All electrodes were calibrated against known concentrations of $A \beta_{40}$ before the experiment, and only MIEs showing increasing response to increasing concentrations of $\mathrm{A} \beta_{40}$ in vitro were used for in vivo experiments.

A $\boldsymbol{\beta}$ ELISA. ISF A $\beta$ levels were assessed using sandwich ELI SAs as previously described (Cirrito et al., 2011). In brief, to assess $A \beta_{40}$ and $A \beta_{42}$ in MIE calibration solutions, mouse monoclonal antibodies (HJ2 or HJ7.4, respectively) were used to capture and a biotinylated central domain $A \beta-$ specific antibody (HJ5.1) was used to detect, followed by streptavidin-poly-HRP-20 (Fitzgerald Industries). All ELI SA assays were developed using Super Slow ELISA TMB (Sigma-Aldrich) and absorbance read on an Epoch plate reader (Bio-Tek) at $650 \mathrm{~nm}$.

A $\boldsymbol{\beta}$ elimination half-life. ISF A $\beta$ half-life was determined similar to our previously described method using microdialysis (Cirrito et al., 2003). MIEs were inserted into the hippocampus and SWV scans were run until the baseline became stable (10-20 min). After baseline stabilization, mice were administered a potent, blood-brain permeable $\boldsymbol{\gamma}$-secretase inhibitor, Compound E (synthesized by AsisChem; 30 mg/kg) intraperitoneally to rapidly block $A \beta$ production. ISF $A \beta$ levels were measured by SWV scans every $60 \mathrm{~s}$ for $60-90 \mathrm{~min}$. The half-life of ISF A $\beta$ was calculated on the basis of the slope of the semilog plot of percent change in $A \beta$ versus time. Only $A \beta$ values that were continually decreasing were included in half-life analysis (within the $60 \mathrm{~min}$ after Compound $\mathrm{E}$ administration).

Quantitative real-time PCR (qRT-PCR). 3-mo-old mice were treated with XR 9576 (80 mg/kg i.v.) or vehicle (equal volume $5 \%$ dextrose). Mice were sacrificed $2 \mathrm{~h}$ later, and their brains were microdissected and frozen on dry ice. Total RNA were extracted from cortex using the RNeasy Mini kit (QIAGEN) and reverse transcribed using the High Capacity cDNA Reverse Transcription kit (Invitrogen). The APP processingrelated genes evaluated were as follows: Amyloid precursor protein (APP), Presenilin 1 and 2 (PSEN1 and PSEN2) Nicastrin, Anterior pharynx-defective 1 (APH-1), $\beta$-secretase 1 (BACE1), A Disintegrin and metalloproteinase domaincontaining protein 10 and 17 (ADAM10 and ADAM17). The $A \beta$ clearance-related genes evaluated were as follows: P-glycoprotein (Pgp), low density lipoprotein 1 (LRP1), insulin degrading enzyme (IDE), Neprilysin (NEP), and matrix metalloproteinase 2 and 9 (MMP2 and MMP9). Individual primers were designed using Harvard Medical School Primer Bank. qRT-PCR was performed using the Fast SYBR Green Master Mix (Applied Biosystems) in ABI 7900HT (Applied Biosystems) with the default thermal cycling program. Dissociation curves were analyzed after qPCR assay to confirm primer efficacy. Relative mRNA levels were calculated using the $\Delta \Delta \mathrm{Ct}$ method, normalizing cDNA levels to endogenous mouse GAPDH. Student's $t$ tests with p-value correction for multiple comparisons were used to analyze changes in gene expression using the GraphPad Prism 6 software.

LRP1 protein levels in brain tissue. Hippocampi from control and XR9576-treated mice were lysed in buffer containing $150 \mathrm{mM} \mathrm{NaCl}, 50 \mathrm{mM}$ Tris, $0.5 \%$ deoxycholic acid, 1\% Triton $\mathrm{X}-100,0.1 \%$ SDS, $2.5 \mathrm{mM}$ EDTA, and broad spectrum protease inhibitors. Protein concentration was determined in each sample using a Micro BCA Protein Assay kit (Thermo Fisher Scientific). $15 \mu \mathrm{g}$ of protein for each sample was used for SDS-PAGE using 4-12\% Bis-Tris gels with MES running buffer (Life Technologies). Rabbit polyclonal anti-LRP1 antibody was produced in G. Bu's laboratory (Mayo Clinic, Jacksonville, FL), followed by goat anti-rabbit HRP (Santa Cruz Biotechnology). As a loading control, blots were stripped and reprobed with mouse anti-GAPDH (Sigma-Aldrich) and sheep anti-mouse peroxidase (GE Life Sciences). Blots were imaged on a ImageStation 440CF (Kodak) and bands quantified using 1D image analysis software (Kodak). LRP1 bands were normalized to GAPDH bands, and then for each gel the control-treated and XR 9576-treated tissues were normalized to the mean of control bands intensity. LRP1 protein levels were compared between groups by unpaired Student's $t$ test.

Compound E and XR9576 levels in brain tissue. Samples were extracted with indicated volume of $45 \%$ methanol $/ 45 \%$ acetonitrile/8\% water/2\% formic acid containing $1 \mu \mathrm{M}$ LY411575 as internal standard so that each hemisphere was extracted at a concentration of $200 \mathrm{mg} / \mathrm{ml}$. After lysis by shaking for $5 \mathrm{~min}$ at $20 \mathrm{~Hz}$ in the TissueLyserII (QIAGEN) with a 4-mm stainless steel ball, samples were centrifuged and then filtered through a $0.8-\mu \mathrm{m}$ PES spin filter (Sartorius). Filtered samples were diluted 1:20 with LC-MS grade water and centrifuged to remove any particulates. Samples were analyzed on a Q-Exactive Mass Spectrometer (Thermo Fisher Scientific) operated in positive profile mode at a resolution setting of 70,000 with a scan range of $\mathrm{m} / \mathrm{z} 100-500$. Spectra were internally calibrated using the lock mass feature against ever present airborne contaminants. The system was equipped with a 1200 Capillary LC (Agilent) and a $0.5 \times 100 \mathrm{~mm} 3 \mu \mathrm{m}$ PLRPS column (Higgins Analytical). Solvents were 100\% water (A) and acetonitrile (B) with $0.1 \%$ formic acid. The chromatographic gradient was as follows: $\% \%$ B from $0-4$ min followed by a linear ramp up to $100 \%$ B over $6 \mathrm{~min}$, a hold at $100 \% \mathrm{~B}$ for $3 \mathrm{~min}$, a 2 -min ramp back down to $0 \% \mathrm{~B}$, and, finally, a reequilibration time of $15 \mathrm{~min} .1 \mu \mathrm{l}$ of sample was injected such that $50 \mathrm{fmol}$ of internal standard was loaded on column each time for data normalization. Data were analyzed using the QuanBrowser application of Xcalibur (Thermo Fisher Scientific). Compound E and XR9576 concentrations in mouse brain were calculated based on comparing normalized area counts with an external calibration curve prepared in control mouse brain extract. 
Statistical analysis. All in vitro measurements were performed in triplicate and the mean of the three SWV scans was used for analysis. All current responses recorded were subtracted from background and fit to baseline for peak analysis using CH Instruments software. Results are expressed as mean \pm SE. Differences in clearance rates between groups were analyzed in GraphPad Prism software using T-tests; repeated measures ANOVA with Bonferroni post-hoc tests was used to analyze percent changes in baseline levels over time. Statistical significance in all analyses was set at $\mathrm{P}<0.05$.

\section{ACKNOWLEDGMENTS}

We would like to thank Dr. Mitch Roitman and his laboratory for valuable discussions and advice regarding the in vivo electrochemical studies, and the Proteomics and Mass Spectrometry Facility at the Danforth Plant Science Center for the measurement of Compound E and XR9576 levels.

This work was supported by National Institutes of Health grants R21 AG045691 (J.R. Cirrito and C.M. Yuede), R01 AG042513 (J.R. Cirrito), P01 NS074969 (J.R. Cirrito) P50 AG568132 (J.R. Cirrito), R01 DA037838 (C.-z. Li), R15 ES021079 (C.-z. Li), and NSF 1334417 (C.-z. Li) and the Brightfocus Foundation (J.R. Cirrito).

The authors declare no competing financial interests.

\section{Submitted: 3 September 2015}

Accepted: 4 March 2016

\section{REFERENCES}

Bankstahl, J.P., C. Kuntner, A. Abrahim, R. Karch, J. Stanek, T. Wanek, W. Wadsak, K. Kletter, M. Müller, W. Löscher, and O. Langer. 2008. Tariquidar-induced P-glycoprotein inhibition at the rat blood-brain barrier studied with (R)- ${ }^{11} \mathrm{C}$-verapamil and PET. J. Nucl. Med. 49:13281335. http://dx.doi.org/10.2967/jnumed.108.051235

Castellano, J.M., R. Deane, A.J. Gottesdiener, P.B. Verghese, F.R. Stewart, T. West, A.C. Paoletti, T.R. Kasper, R.B. DeMattos, B.V. Zlokovic, and D.M. Holtzman. 2012. Low-density lipoprotein receptor overexpression enhances the rate of brain-to-blood $A \beta$ clearance in a mouse model of $\beta$-amyloidosis. Proc. Natl. Acad. Sci. USA. 109:15502-15507. http://dx doi.org/10.1073/pnas.1206446109

Cirrito, J.R., P.C. May, M.A. O’Dell, J.W.Taylor, M. Parsadanian, J.W. Cramer, J.E. Audia, J.S. Nissen, K.R. Bales, S.M. Paul, et al. 2003. In vivo assessment of brain interstitial fluid with microdialysis reveals plaque-associated changes in amyloid-beta metabolism and half-life. J. Neurosci. 23:8844-8853

Cirrito, J.R., R. Deane,A.M. Fagan, M.L. Spinner, M. Parsadanian, M.B. Finn, H. Jiang, J.L. Prior, A. Sagare, K.R. Bales, et al. 2005. P-glycoprotein deficiency at the blood-brain barrier increases amyloid-beta deposition in an Alzheimer disease mouse model. J. Clin. Invest. 115:3285-3290. http://dx.doi.org/10.1172/JCI25247

Cirrito, J.R., B.M. Disabato, J.L. Restivo, D.K. Verges, W.D. Goebel, A. Sathyan, D. Hayreh, G. D’Angelo, T. Benzinger, H. Yoon, et al. 2011 Serotonin signaling is associated with lower amyloid- $\beta$ levels and plaques in transgenic mice and humans. Proc. Natl. Acad. Sci. USA. 108:1496814973. http://dx.doi.org/10.1073/pnas.1107411108

Deane, R., Z. Wu, A. Sagare, J. Davis, S. Du Yan, K. Hamm, F. Xu, M. Parisi, B. LaRue, H.W. Hu, et al. 2004. LRP/amyloid beta-peptide interaction mediates differential brain efflux of Abeta isoforms. Neuron. 43:333-344. http://dx.doi.org/10.1016/j.neuron.2004.07.017

Deo, A.K., S. Borson, J.M. Link, K. Domino, J.F. Eary, B. Ke, T.L. Richards, D.A. Mankoff, S. Minoshima, F. O'Sullivan, et al. 2014. Activity of p-glycoprotein, a $\beta$-amyloid transporter at the blood-brain barrier, is compromised in patients with mild Alzheimer disease. J. Nucl. Med. 55:1106-1111. http://dx.doi.org/10.2967/jnumed.113.130161
Farris, W., S.G. Schütz, J.R. Cirrito, G.M. Shankar, X. Sun, A. George, M.A. Leissring, D.M. Walsh, W.Q. Qiu, D.M. Holtzman, and D.J. Selkoe. 2007. Loss of neprilysin function promotes amyloid plaque formation and causes cerebral amyloid angiopathy. Am. J. Pathol. 171:241-251. http:// dx.doi.org/10.2353/ajpath.2007.070105

Hartz, A.M., D.S. Miller, and B. Bauer. 2010. Restoring blood-brain barrier P-glycoprotein reduces brain amyloid-beta in a mouse model of Alzheimer's disease. Mol. Pharmacol. 77:715-723. http://dx.doi.org/10 .1124/mol.109.061754

Jankowsky, J.L., D.J. Fadale, J. Anderson, G.M. Xu, V. Gonzales, N.A. Jenkins, N.G. Copeland, M.K. Lee, L.H.Younkin, S.L. Wagner, et al. 2004. Mutant presenilins specifically elevate the levels of the 42 residue beta-amyloid peptide in vivo: evidence for augmentation of a 42-specific gamma secretase. Hum. Mol. Genet. 13:159-170. http://dx.doi.org/10.1093/ hmg/ddh019

Kanekiyo, T., J.R. Cirrito, C.C. Liu, M. Shinohara, J. Li, D.R. Schuler, M. Shinohara, D.M. Holtzman, and G. Bu. 2013. Neuronal clearance of amyloid- $\beta$ by endocytic receptor LRP1. J. Neurosi. 33:19276-19283. http://dx.doi.org/10.1523/JNEUROSCI.3487-13.2013

Kozai, T.D.Y., A.L. Vazquez, C.L. Weaver, S.G. Kim, and X.T. Cui. 2012. In vivo two-photon microscopy reveals immediate microglial reaction to implantation of microelectrode through extension of processes. J. Neural Eng. 9:066001. http://dx.doi.org/10.1088/1741-2560/9/6/066001

Mawuenyega, K.G., W. Sigurdson,V. Ovod, L. Munsell, T. Kasten, J.C. Morris, K.E. Yarasheski, and R.J. Bateman. 2010. Decreased clearance of CNS beta-amyloid in Alzheimer's disease. Science. 330:1774. http://dx.doi.org $/ 10.1126 /$ science. 1197623

Musiek, E.S., and D.M. Holtzman. 2015. Three dimensions of the amyloid hypothesis: time, space and 'wingmen'. Nat. Neurosci. 18:800-806. http ://dx.doi.org/10.1038/nn.4018

Nixon, R.A. 2007. Autophagy, amyloidogenesis and Alzheimer disease. J. Cell Sci. 120:4081-4091. http://dx.doi.org/10.1242/jcs.019265

Prabhulkar, S., R. Piatyszek, J.R. Cirrito, Z.Z. Wu, and C.Z. Li. 2012. Microbiosensor for Alzheimer's disease diagnostics: detection of amyloid beta biomarkers. J. Neurochem. 122:374-381. http://dx.doi.org/10.1111 /j.1471-4159.2012.07709.x

Preston, S.D., P.V. Steart, A. Wilkinson, J.A.R. Nicoll, and R.O. Weller. 2003. Capillary and arterial cerebral amyloid angiopathy in Alzheimer's disease: defining the perivascular route for the elimination of amyloid $\beta$ from the human brain. Neuropathol. Appl. Neurobiol. 29:106-117.http://dx.doi .org/10.1046/j.1365-2990.2003.00424.x

Qosa, H., B.S. Abuasal, I.A. Romero, B. Weksler, P.-O. Couraud, J.N. Keller, and A. Kaddoumi. 2014. Differences in amyloid- $\beta$ clearance across mouse and human blood-brain barrier models: kinetic analysis and mechanistic modeling. Neuropharmacology. 79:668-678. http://dx.doi.org/10.1016/j .neuropharm.2014.01.023

Roitman, M.F., R.A. Wheeler, R.M. Wightman, and R.M. Carelli. 2008 Real-time chemical responses in the nucleus accumbens differentiate rewarding and aversive stimuli. Nat. Neurosci. 11:1376-1377. http://dx .doi.org/10.1038/nn.2219

Sadik, O.A., W.H. Land, and J. Wang. 2003. Targeting chemical and biological warfare agents at the molecular level. Electroanalysis. 15:1149-1159. http ://dx.doi.org/10.1002/elan.200390140

Seiffert, D., J.D. Bradley, C.M. Rominger, D.H. Rominger, F. Yang, J.E. Meredith Jr., Q. Wang, A.H. Roach, L.A. Thompson, S.M. Spitz, et al. 2000. Presenilin-1 and -2 are molecular targets for gamma-secretase inhibitors. J. Biol. Chem. 275:34086-34091. http://dx.doi.org/10.1074 /jbc.M005430200

Shibata, M., S. Yamada, S.R. Kumar, M. Calero, J. Bading, B. Frangione, D.M. Holtzman, C.A. Miller, D.K. Strickland, J. Ghiso, and B.V. Zlokovic. 2000. Clearance of Alzheimer's amyloid-ss(1-40) peptide from brain by LDL receptor-related protein-1 at the blood-brain barrier. J. Clin. Invest. 106:1489-1499. http://dx.doi.org/10.1172/JCI10498 
van Assema, D.M., M. Lubberink, M. Bauer, W.M. van der Flier, R.C. Schuit, A.D. Windhorst, E.F.I. Comans, N.J. Hoetjes, N. Tolboom, O. Langer, et al. 2012. Blood-brain barrier P-glycoprotein function in Alzheimer's disease. Brain. 135:181-189. http://dx.doi.org/10.1093/brain/awr298

Vestergaard, M., K. Kerman, M. Saito, N. Nagatani,Y.Takamura, and E.Tamiya. 2005. A rapid label-free electrochemical detection and kinetic study of Alzheimer's amyloid beta aggregation. J. Am. Chem. Soc. 127:1189211893. http://dx.doi.org/10.1021/ja052522q

Vogelgesang, S., I. Cascorbi, E. Schroeder, J. Pahnke, H.K. Kroemer, W Siegmund, C. Kunert-Keil, L.C. Walker, and R.W. Warzok. 2002 Deposition of Alzheimer's beta-amyloid is inversely correlated with P-glycoprotein expression in the brains of elderly non-demented humans. Pharmacogenetics. 12:535-541. http://dx.doi.org/10.1097 /00008571-200210000-00005

Wanek, T., K. Römermann, S. Mairinger, J. Stanek, M. Sauberer, T. Filip, A. Traxl, C. Kuntner, J. Pahnke, F. Bauer, et al. 2015. Factors governing P-glycoprotein-mediated drug-drug interactions at the blood-brain barrier measured with positron emission tomography. Mol. Pharm.
12:3214-3225. http://dx.doi.org/10.1021/acs.molpharmaceut $.5 b 00168$

Wang, D.S., R.B. Lipton, M.J. Katz, P. Davies, H. Buschke, G. Kuslansky, J. Verghese, S.G.Younkin, C. Eckman, and D.W. Dickson. 2005. Decreased neprilysin immunoreactivity in Alzheimer disease, but not in pathological aging. J. Neuropathol. Exp. Neurol. 64:378-385. http://dx.doi.org/10 $.1093 /$ jnen/64.5.378

Wightman, R.M. 1988. Voltammetry with microscopic electrodes in new domains. Science. 240:415-420. http://dx.doi.org/10.1126/science.240 .4851 .415

Xie, L., H. Kang, Q. Xu, M.J. Chen,Y. Liao, M.Thiyagarajan, J. O’Donnell, D.J. Christensen, C. Nicholson, J.J. Iliff, et al. 2013. Sleep drives metabolite clearance from the adult brain. Science. 342:373-377. http://dx.doi.org $/ 10.1126 /$ science. 1241224

Zlokovic, B.V., R. Deane, A.P. Sagare, R.D. Bell, and E.A. Winkler. 2010. Low-density lipoprotein receptor-related protein-1: a serial clearance homeostatic mechanism controlling Alzheimer's amyloid $\beta$-peptide elimination from the brain. J. Neurochem. 115:1077-1089. http://dx.doi .org/10.1111/j.1471-4159.2010.07002.x 